\title{
Soil Colloids, Types and their Properties: A review
}

\author{
Beamlaku Alemayehu ${ }^{1 *}$ and Habtemariam Teshome ${ }^{2}$ \\ ${ }^{1}$ Adet Agricultural Research Center, P.O. Box. 08, Bahir Dar, Ethiopia \\ ${ }^{2}$ Srinka Agricultural Research Center, Woldia, Ethiopia
}

Received: 05 July, 2021

Accepted: 10 August, 2021

Published: 11 August, 2021

*Corresponding author: Beamlaku Alemayehu, Adet Agricultural Research Center, P.O. Box. 08, Bahir Dar, Ethiopia, E-mail: amlakalema@gmail.com

Keywords: Soil; Colloid; Organic; Inorganic; Clay

https://www.peertechzpublications.com

\section{Check for updates}

\begin{abstract}
The colloidal complex of soils is the fine and supreme functional section of the organic and inorganic soil particles where most of the chemical properties take place. The inorganic or clay colloidal complex of soils occurs as too fine particles and organic colloidal complex happen in the form of humus particles. Soil colloidal fraction is the site of important processes in soil, governing ion exchange, nutrient availability and fixation, and soil physical properties. Based on the silicate and crystalline nature of the colloid mineral colloids are classified into three. These are crystalline layer silicate clays, noncrystalline layer silicate clays, and non-silicate clays. The organic colloidal complex in soils is mainly because of the existence of hummus. Shape, surface area, plasticity, cohesion, swelling, shrinkage, dispersion, and flocculation are the most important properties of soil colloids.
\end{abstract}

\section{Introduction}

Soil colloids can be defined as the particle of soil with a diameter less than $1 \mu \mathrm{m}$. Soil is composed of a mixture of solids, liquids, and gases phases. The solid fragment of soils comprises an inorganic and organic material. The liquid phase called soil solution is composed of dissolved inorganic minerals, salts, and organic compounds and is responsible for nutrient transport [1]. The mineral components of soils are largely determined by the parent material from which the soil is made up. Primary minerals that are inherited from the parent rocks include feldspar, quartz, and mica, while secondary minerals like lime, gypsum, and oxides and hydroxides of $\mathrm{Fe}$ and $\mathrm{Al}$ are those transformed through chemical weathering and found in the clay fraction $[2,3]$.

The fertility of the soil for plants is mainly governed by the soil's cation-exchange capacity. Soil colloids have high cation exchange capacity because of their high surface area and high charges [4]. Without soil colloids, exceedingly essential nutrients would be removed from the soil by draining water and moved in channels. The relevant amount of basic cations held by a soil regulate the base status of the soil. An excessive base position means that the soil holds a high supply of base cations essential for plant growth. The soil will be in low base status and less fertile when soil colloids hold a little supply of bases. Inorganic (clay) and organic (humus) colloidal complexes of the soil have high fertility [5]. Due to their small size colloids move towards suspension in a solution, they stay on the surface for a long time without sink.

The clay fraction of soil is $<2 \mu \mathrm{m}$ in diameter, not all clay particles are exactly colloid. However, larger size clay particles have colloid-like characteristics. Some of the colloidal complexes of soils are inorganic minerals, whereas others are organic colloids [6]. The inorganic colloidal complex of soils is mostly fine clay particles that display thin plate-like bodies under a microscope. When these particles are homogenized in water, they stay afloat in absolutely, changing the water dark. The organic colloidal complex of soils is small particles of organic matter that are infrequently resistant to change and appear for humus. A homogeneous dispersion of colloidal particles in a liquid is called colloidal dispersion. If particles are large and settle rapidly, the dispersion is called a suspension. Clay particles and soil organic matters are the most common examples of soil colloidal complexes [5]. There are two types of clays: (1) the silicate clays have characteristics of temperate regions and (2) the $\mathrm{Fe}^{3+}$ and $\mathrm{Al}^{{ }^{3+}}$ oxide and hydro oxides clays. These are better known in old soils of the tropics and sub-tropics [5]. Because of their small size soil colloids have a large surface area per unit mass and its volume ratio [7]. This property distinguishes the colloids' behavior from larger particles in aqueous suspension. Colloid behavior is dominated by surface charge, which influences the stability of the colloidal suspension and consequently the mobility of colloid in the landscape. Colloids are mobile in soil and subsoil, aquifers, and 
fluvial and marine systems. Colloid movement is important in soil formation and with the movement of pollutants in the environments [8].

\section{Soil colloids}

The colloidal complex of soils is the main alive section of the soil and determines most of the physicochemical properties of soils [7]. They are essential because the charged ions on their surfaces attract soil nutrients when dissolved in soil, water as positively charged ions. Soil colloids can be organic or inorganic particles with a diameter of less than1micro a meter or $(<0.001 \mathrm{~mm})$ in diameter $[6,7]$.

The soil colloid is amorphous in shape and does not form a true solution when mixed with other substances. The colloidal particles never settle at the bottom in solvents rather they remain float in suspension. Soil colloids are not found in ionic or molecular states but are found in accumulating atoms or molecules. A colloid is defined and described as "glue-like" organic or inorganic matter with too little particle size but large surface area per unit mass or volume [1]. Clays, metal oxides, and organic soil particles are described as soil colloids [1].

\section{Types of soil colloids}

Depending on the nature of the linkages present and the types of compounds formed, soil colloids can be broadly classified into two: Namely:

(a) Inorganic colloids or clay colloids and (b) Organic colloids represented by humus

These colloids are too aggregated to each other and it is not easy to segregate them. The inorganic soil colloidal complex fractions occur as too small particles and the organic soil colloidal complex fractions appear in the form of humus particles. The soil colloidal complex fractions display most of the properties of the ordinary colloidal structure, like adsorption, Tyndal effect, Brownian movement, coagulation, electrophoresis, and dialysis [9].

Inorganic (clay) soil colloids: Inorganic (clay) colloids as sphere-like particles and their sizes are described in their diameters, although the latest electron micrographs show that particles take place in layers and each clay particle come to visible since it is composed of plates like units. These units of clay are aggregated by a force of attraction. Plate-like clay particles lay bar a high surface area on which moisture and cations are held. When the clay particles become smaller and smaller in size, there will be a higher percentage of hygroscopic moisture. Based on the silicate and crystalline nature of the colloid mineral colloids are classified into three. These are Crystalline layer silicate clays, noncrystalline layer silicate clays (allophane and imogolite), and non-silicate clays (iron and aluminum oxide clays) [2,9]. Crystalline minerals made up of atoms layout in a three-dimensional design, while noncrystalline minerals are don't have this structural pattern [10].

Based on structure, clay minerals are classified into two main categories [11]. These are structured and amorphous. Structured clays are also classified into two typical groups that are 1:1 and 2:1 type of minerals. The 2:1 type clay minerals are also further classified into expanding and nonexpanding.

Alumino-silicates minerals are the most principal minerals in the clay fraction of temperate region soils whereas in tropical climates iron and aluminum hydrated oxides are more typical. The classic alumino-silicate clay minerals are displayed in two main structural units such as a tetrahedron of four oxygen atoms surrounding a central cation, mainly $\mathrm{Si}^{4+}$, and an octahedron of six oxygen atoms surrounding a larger basic ion of lesser valency, usually $\mathrm{Al}^{3+}$ or $\mathrm{Mg}^{2+}$ [11]. The tetrahedra joined them at the bottom layer corners, through common oxygen, in a hexagonal structure that forms a flat sheet. The octahedra are joined in the same way along their edges to form a triangular array. The basic structure of alumni-silicate clays is showed in Figure 1.

A tetrahedron of oxygen atoms surrounding the silicon ion (left) and an octahedron of oxygen or hydroxyls enclosing an aluminum ion (right) (11).

\section{Crystalline layer silicate clays}

A crystal can be defined as a mineral, or another crystalline chemical compound (a solid with a specific chemical composition), with an external shape bounded by smooth plane surfaces. Such a crystal shape is the outward expression of its ordered internal, atomic arrangement. Crystals can be described as perfect, good, or malformed, depending on how well the external shape reflects the overall symmetry inherent in the internal atomic arrangement [1]. The typical layer in the crystal structure is a pair of silica-alumina sheets which usually form a hexagonal plate sheet [11]). The layer silicate clay minerals are also called phyllosilicates [3]. Phyllon means leaf in Greek which is made up of silica tetrahedral and aluminum or magnesium octahedral sheets networked by a common oxygen atom [3].

Layer silicate clays are silicate minerals formed from two-dimensional tetrahedral/octahedral sheets, formed in a regular array in the $\mathrm{Z}$ direction [6]. The main crystal structure of the layer silicate clays comprises sheets of $\mathrm{Si}$ in tetrahedral coordination with $\mathrm{O},\left[\mathrm{SiO}_{2}\right] \mathrm{n}$ and sheets of $\mathrm{Al}$ in octahedral coordination with $\mathrm{OH},\left[\mathrm{Al}_{2}(\mathrm{OH})_{6}\right] \mathrm{n}$ and many clay minerals have a phyllosilicate type of structure. Based on the number and arrangement of silica and alumina-magnesia sheets available in the crystal layers, Phyllosilicates are divided into three main classes. These are 1:1 type, 2:1 type, and 2:1:1 type of minerals.

Phyllosilicate clay minerals are dominant inorganic colloids in most soils. Two types of silicate clays have been recognized crystalline (kaolinite and montmorillonite) and non-crystalline

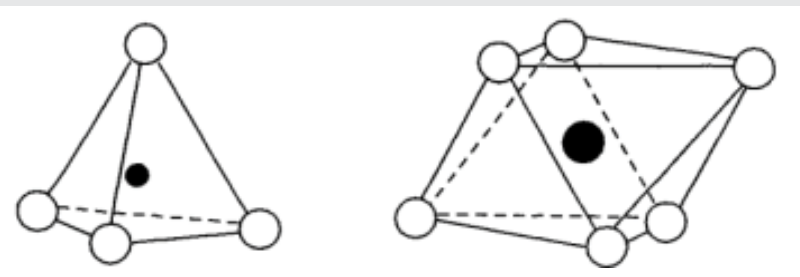

Figure 1: The basic structural unit of aluminosilicate clay minerals.

Citation: Alemayehu B, Teshome H (2021) Soil Colloids, Types and their Properties: A review. Open J Bioinform Biostat 5(1): 008-013. 
silicate clays (for instance allophane). The crystalline structure of the silicate clay assemblages consists of two to four sheets of tightly held $\mathrm{O}_{2}, \mathrm{Si}$, and $\mathrm{Al}$ atoms that largely carry negative charges. The basic elements of layer silicate clay minerals are the Si tetrahedron and $\mathrm{Al}$ octahedron sheets. The octahedral sheet consists of hydroxyl (6OH-) groups coordinated around a central cation, mainly $\mathrm{Al}^{3+}, \mathrm{Fe}^{2+}$ or $\mathrm{Mg}^{2+}$. The soil is thus an $\mathrm{O}-\mathrm{Si}-\mathrm{Al} / \mathrm{Fe}$ matrix containing essential elements with negative oxygen ends and positive $\mathrm{Si}-\mathrm{Al} / \mathrm{Fe}$ ends. The combination of the tetrahedron and octahedron structures creates different types of silicate clay minerals (i.e., aluminosilicates). According to the number of tetrahedron and octahedron sheets, silicate clay minerals are classified as follows, drawn in part from $[2,9]$.

Type of crystalline layer silicate clays: The layers of 1:1 type crystalline layer silicate clays are composed of one silica on one side combined with one alumina sheet on the other side. Because of this manner, it is called a 1:1 type crystal. Kaolinite is the main typical element of this group. It is the major clay mineral in most weathered tropical soils like Oxisols and Ferrosols [12]. In a given layer of kaolinite, the silica and alumina sheets are connected by common oxygen anions [11] As a result of this the lattice is fixed and there is no expansion and little isomorphic substitution with low cation exchange capacity (CEC) in kaolinite minerals usually occurs between layers when the clay is wetted. The 1:1 structure has layers that have a flat surface of oxygen on one side and hydroxyls on the other. The aggregate of layers in clays results in a strong attraction between the oxygen of one layer and the hydrogen bonding of the next layer makes it a nonexpanding. Positive ions and water do not enter between the structural units of the kaolinite clay and the effective surface of kaolinite is though fixed to its outside faces. Because of this situation, Kaolinite has very low plasticity, cohesion, shrinkage, and swelling properties [2]. The formula of kaolinite is represented by $\mathrm{Al}_{4} \mathrm{Si}_{4} \mathrm{O}_{10}(\mathrm{OH})_{8}$ [11]. It forms at low temperature and pressure as an authigenic mineral (authigenic meaning that the mineral formed in place and was not transported there from elsewhere; from the Greek words authi, meaning "in place," and genesis, meaning "origin") $[11,13]$. Soils with high kaolinite clay content will have good physical properties. Kaolinite clay particles are pseudo-hexagonal plate-like shaped by nature ranging from micron to nano-size particles [14]. The structure of 1:1 layer silicate is shown in Figure 2.

Type of crystalline layer silicate clays: The crystal layers of these minerals occur when an octahedral sheet is bounded between two tetrahedral sheets $[16,17]$. This class consists the mica, vermiculite, and smectite clay minerals which have 2:1 structures. But smectite and vermiculite are grouped under expanding type while fine micas and biotite are relatively nonexpanding. The minerals vary majorly in the extent and location of isomorphous substitution, and the type of internal layer cation prevails $[10,16,18]$. Montmorillonite is the most prominent of the smectite groups exhibiting high isomorphic substitution of aluminum in the silicon position and having a high CEC (i.e., high negative charge sites) [2]. The structure of layered silicate clays is shown in Figure 3.
This 2:1 type of basic crystal structure can be grouped into expanding and non-Expanding.

\section{Expanding minerals}

Expanding type of clay minerals are those with interlayer surfaces are freely capable to water movement [12]. Smectite and vermiculite are good examples of expanding types of crystalline silicate clay while fin grain mica is nonexpanding crystalline silicate clay.

Smectite: Is a member of silicate clays in the 2:1 type which have high shrinking and swelling properties because of its interlayer expansion in dry and wet conditions $[15,18]$.

It has high CEC because of its high negative charges on its large surface area. The shrinkage is happened because of the loss of water from the between layer and between particles and wide cracks created when it dries out [18].

Montmorillonite is the most prominent member of this group in soils. The movement of water and cations into the interlayer spaces of the smectite crystals exposes a very large internal surface that, by far, exceeds the external surface area $[10,18]$. Because of the tendency to expand and to disperse, montmorillonite exhibits pronounced swelling and shrinking behavior, as well as high plasticity and cohesion. On drying, montmorillonite soils, especially if dispersed, tend to crack and form unusually hard clods and when heated to several hundred degrees they tend to close irreversibly so that only their external areas act as adsorbing surfaces. The unit layer formula of montmorillonite is $\mathrm{Al}{ }_{3.5} \mathrm{Mg}_{0.5} \mathrm{Si}_{8} \mathrm{O}_{20}(\mathrm{OH})_{4}$ [11]. Because of the weak interlayer bonding and free movement of water and cations into and out of this region, the smectites have been called shrink-swell or expanding clays [12].

The name montmorillonites derived from Montmorillon, a town in the Poitou area, France are the most plentiful minerals in the smectite group of 2:1 clay minerals [19]. The montmorillonite particles size ranges between 0.1 and $2 \mathrm{~mm}$ in diameter with $0.5 \mathrm{~mm}$ average sizes. The shape of montmorillonite clay particles is irregular, compact and most

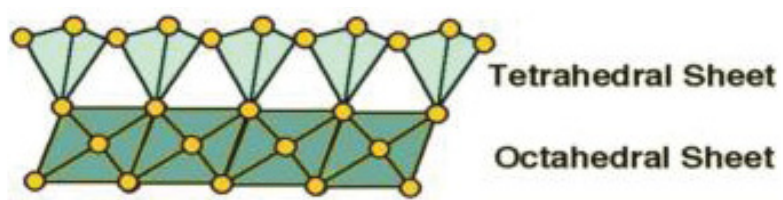

Figure 2: Structure of 1:1 layer silicate/Kaolinite, which shows tetrahedral and octahedral sheets [15]

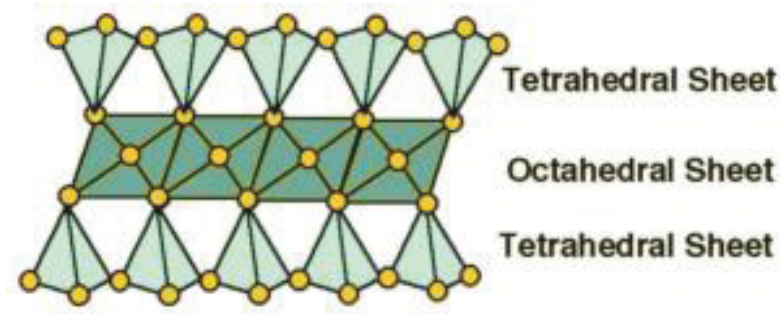

Figure 3: Structure of 2:1 layered silicate clay connection sheet [15].

Citation: Alemayehu B, Teshome H (2021) Soil Colloids, Types and their Properties: A review. Open J Bioinform Biostat 5(1): 008-013. 
of the time seems like paper sheets [19]. The regarded formula of montmorillonite is represented by $(\mathrm{Na}, \mathrm{Ca})_{0.3}(\mathrm{Al}, \mathrm{Mg})_{2} \mathrm{Si}$ ${ }_{4} \mathrm{O}_{10}(\mathrm{OH})_{2} \cdot \mathrm{nH}_{2} \mathrm{O}$ [19]. This layer structure can swell due to absorb water molecules between the tetrahedral-octahedraltetrahedral sheets concerning the $\mathrm{Na}^{+}$and $\mathrm{Ca}^{2+}$ interlayer positive ions. The structure of this clay mineral is overall somewhat electrically unbalanced, with a slight negative charge, which allows for the absorption of exchangeable cations on all sides of the surface of the fine clay particles [20].

Vermiculites: Have similar arrangement properties with the smectite group in which an octahedral sheet is sandwiched between two tetrahedral sheets. Most vermiculites have a dioctahedral arrangement and isomorphous substitution similar to smectites. While in the trioctahedral vermiculites, the octahedral sheet is substituted by $\mathrm{Mg}$ rather than $\mathrm{Al}$. But in a tetrahedral sheet of vermiculite, the substantial substitution of aluminum for silicon taken place. This was measured for many of the very high net negative charge related $[15,18]$.

Besides magnesium and other ions, $\mathrm{H}_{2} \mathrm{O}$ molecules are also absolutely adsorbed in the interlayer space of vermiculite. They serve as bridges connecting the units. The extent of swelling is markedly less for vermiculite than smectite. As a result, vermiculite is noticed in a limited expansion of clay minerals. Its extent of expansion is higher than kaolinite, however, less than montmorillonite. Because of the presence of water molecules and $\mathrm{Mg}^{2+}$ between interlayer spaces, vermiculites are less expansive than smectites [3]. The CEC of vermiculites is normally higher than that of montmorillonite and smectite clay minerals [5]. Vermiculites are well-known trioctahedral structures in which both di- and trivalent positive ions fil all the existing sites in the octahedral sheet [12]. Vermiculite categories are moreover different from the smectite categories by the strong magnitude of isomorphic substitution in tetrahedral sheets [17].

Negative charges resulted from isomorphous substitutions of $\mathrm{Al}$ for $\mathrm{Si}$ and $\mathrm{Al}$ or $\mathrm{Fe}$ for $\mathrm{Mg}$ in tetrahedral and octahedral layers respectively. Vermiculite is a general name applied for minerals having similar layer charge, cation exchange capacity, and hydration properties [18]. The ideal formula for vermiculites is represented by $\mathrm{Mg}_{3}(\mathrm{Si}, \mathrm{Al}){ }_{4} \mathrm{O}_{10} \cdot 4.5 \mathrm{H}_{2} \mathrm{O}[\mathrm{Mg}]_{0.35}$, in which $[\mathrm{Mg}]$ stands for exchangeable ions in the structure. Its structure can expand due to the absorption of water. When it is rapidly heated, it produces a lightweight expanded product that is widely used in thermal insulation and potting soil. This exfoliated product is used in agriculture for soil conditioning as a carrier in fertilizers, herbicides, and insecticides. It is also applied as an absorbent for environmentally hazardous $[18,20]$.

\section{Type non-expanding minerals}

Fine-grained mica: Are the typical minerals in this category. For instance, muscovite and biotite which exist in the sand and silt particles are the best examples of this group. Minerals that have a similar structure with fine-grained micas (illite) also exist in clay minerals. Similar to smectites, finegrained mica has also a 2:1 type structure $[10,16]$. However, it is large as compared to smectites. Tetrahedral is the main source of charges than octahedral. Hydration, cation adsorption, swelling, shrinkage, and plasticity properties of this group are lower as compared to smectite [9].

Fine-grain mica is non-expansive because the interlayer is occupied by significant potassium that binds the layer together which limits swelling and CEC when silicon is replaced by aluminum [18]. Fine-grained mica has high negative charges due to excessive (about $20 \%$ ) substitution of $\mathrm{Al}^{3^{+}}$for $\mathrm{Si}^{4^{+}}$take place in the tetrahedral sheet $[3,12]$.

Chlorites: Are also the other non-expanding categories of 2:1 silicate clay because $\mathrm{Mg}$-octahedral is hydrogen-bonded to the oxygen atoms of the two adjacent tetrahedral sheets closely binding the layers together. Magnesium is dominating the trioctahedral position of chlorite as a result the structure has two silica tetrahedral sheets and two magnesium trioctahedral sheets to giving rise to the term 2:1:1 type structure [10]. Chlorite is characteristic of old soils like ultisols and oxisols [17]. The formula for chlorite is mainly represented by $\mathrm{Mg}_{6} \mathrm{Si}_{6}$ $\mathrm{A}_{2} \mathrm{O}_{20}(\mathrm{OH})_{4}$, with $\mathrm{Mg}_{6}(\mathrm{OH})_{12}$ [11,17]. The colloidal complex properties of chlorites are completely similar to fine-grained micas [2]. Chlorite is present in many metamorphic rocks.

\section{Non-crystalline silicate clays}

In the humid tropics, amorphous minerals quickly changed to allophane. The general formula is represented by $\mathrm{A}_{2} \mathrm{O}_{3} \cdot 2 \mathrm{SiO}_{2}$ . $\mathrm{H}_{2} \mathrm{O}$ formed from weakly aggregated silica and alumina elements. It is most prominent in soils formed from volcanic ash soils (Andisols). Allophane and imogolite are common in Andisols which are mainly found in young soils [12].

Allophane and imogolites have both positive and negative surface charges (i.e., variable charge), but their capacity to fix cations varies with $\mathrm{pH}$; cations being adsorbed mostly at higher $\mathrm{pH}$ due to net negative charges at high soil $\mathrm{pH}$. In acid soils, allophanes are known for their anion adsorption, particularly that of phosphate fixation [2,9]. High organic matter, high water holding capacity, and high CEC (cation exchange capacity) are the basic properties of soils with high allophane. The general formula for imogolite is $\mathrm{Si}_{2} \mathrm{Al}_{4} \mathrm{O}_{10} .5 \mathrm{H}_{2} \mathrm{O}$ whereas allophane has $\mathrm{Si}_{\mathrm{y}} \mathrm{Al}_{4} \mathrm{O}_{6+\mathrm{y}} \cdot \mathrm{nH}_{2} \mathrm{O}$ were $1.6 \leq \mathrm{y} \leq 4, \mathrm{n} \geq 5$ [17]. Phosphorus and iron oxides are commonly found. Allophane has similar adsorption ion exchange, and plasticity properties to crystalline clays [11]. An ordered atomic arrangement requires that the internal structure of minerals consists of regularly repeated threedimensional patterns of atoms, ions, or ionic groups that are held together by various chemical bonds. Solids that lack such a regular internal repeated pattern or ordered internal arrangement are referred to as amorphous [20].

\section{Non-silicate clays}

Non-silicate clays are hydrous oxides of iron and aluminum which results in reddish or yellowish color in tropical and subtropical soils. Its general formula is represented by $\mathrm{Fe}_{2} \mathrm{O}_{3} \cdot \mathrm{n}$ $\mathrm{H}_{2} \mathrm{O}$ and $\mathrm{A1}_{2} \mathrm{O}_{3} \mathrm{nH}_{2} \mathrm{o}$. The electrostatic, adsorptive capacity and plasticity properties of non-silicate clays are less obvious silicate clays. Mostly, oxides act as cementing agents in the maintenance of soil aggregates exactly in subtropical and tropical soils [11]. 
Non-silicate clays are comprised of modified octahedral in $\mathrm{Fe}^{3+}$ or $\mathrm{Al}^{3+}$ sheets. They have neither tetrahedral sheets nor silicon in their structures. These clays have dominantly positive charges. In this group oxides of $\mathrm{Al}^{3+}$ and $\mathrm{Fe}^{3+}$ such as $\left[\mathrm{Al}(\mathrm{OH})_{3}\right]$, $(\mathrm{FeOOH}),\left(\mathrm{Fe}_{2} \mathrm{O}_{3}\right)$ are common. Gibbsite $\left[\mathrm{Al}(\mathrm{OH})_{3}\right]$, is common in highly weathered soils like Oxisols and Ultisols [3]. Oxides of $\mathrm{Al}^{3+}$ and $\mathrm{Fe}^{3+}$ clays are found in many soils but in much greater quantities in old soils of tropical and sub-tropical regions such as Acrisols, Alisols, Lixisols, Luvisols, and Nitisols [5]. The iron and aluminum oxide minerals are collectively referred to as sesquioxides. These clays are usually amorphous. The most common iron oxide minerals are goethite and hematite while gibbsite is the prominent aluminum oxide mineral. These are formed in highly weathered soils with silicon depleted through leaching, and giving rise to the red color of the soils. In lower $\mathrm{pH}$ soils, iron and aluminum oxides carry a net positive charge and attract negatively charged ions which partly contribute to the increased phosphate fixation in the soil colloids in acidic soils while at higher $\mathrm{pH}$ values, the particles carry a small negative charge that is balanced by adsorbed cations[2,9].

Organic colloids: Organic colloids also called humus which is the dark-colored, stable colloidal organic decomposed plant and animal remains [1,3]. Humus is a mixture of various complex compounds like lipoproteins, polysaccharides, and polyuronides $[5,18,21]$. Organic colloids in sandy soils are present in small amounts while in peaty soils may be present at greater than $50 \%$. Organic colloids exhibit adsorptive capacity higher than colloids $[18,21]$. They are negatively charged colloids like clay colloids. When organic colloids are added to the sandy soils, increases provisionally its moisture and nutrient holding capacity will be increased. During hydration, each particle of humus forms a micelle and due to the presence of Because of high negative charges available on the surface of the humus which can attract different positively charged organic and inorganic constituents. Organic colloids have high CEC as compared to clay and they can store and slowly release essential nutrients for plant growth [11].

An organic colloid is normally amorphous or shapeless. The source of negative charges for hummus is from the dissociation of carboxylic $(-\mathrm{COOH})$ and phenolic $(\sim-\mathrm{O} \mathrm{H})$ groups. This type of colloids is mostly $\mathrm{pH}$-dependent because the CEC process depends on the replacement of hydrogen and CEC normally increases at higher $\mathrm{pH}$ values. The organic colloids consist of convoluted chains (i.e., non-crystalline) and rings of carbon atoms bonded to hydrogen, oxygen, and nitrogen [5]. Humus particles are often among the smallest of soil colloids and exhibit a very high capacity to absorb water but almost no plasticity or stickiness. They have a net negative charge per unit mass because of partly dissolved hydroxyl, carboxyl, and phenolic content but the charge is $\mathrm{pH}$-dependent and becomes extremely high in neutral to alkaline soils [2].

Properties of soil colloids: Certain characteristics also assume considerable importance such as shape, surface area, plasticity, cohesion, swelling, shrinkage, dispersion, and flocculation. The properties of soil colloids are all surface phenomena and their strength depending on the amount and nature of the interaction hand over by the colloids [9].
Size: The organic and inorganic soil colloids are extremely smaller in size less than $0.001 \mathrm{~mm}$ or less than 1micrometer in diameter. These particles cannot be viewed using an ordinary light microscope but can be visualized only with an electron microscope. The soil colloidal particles never pass through a semi-permeable membrane [9]. Colloids in natural systems are characterized by a continuous particle size distribution of complexity and diversity. The allocation of shapes, densities surface chemical properties, and chemical composition might different extensively with size [18].

Shape: The shape of colloidal clay particles is seen as spherical, crystalline, and or amorphous. Clay particles that are composed of plates of layers and have an internal structure are crystalline [9]. Colloidal shapes mainly depend on their mineralogical arrangement [18].

Surface area: The total surface area of soil colloids is the sum of both internal and external surfaces [12]. For instance, the surface area of fine-grained mica is about $10^{5} \mathrm{~m}^{2} \mathrm{~kg}^{-1}$ on average, whereas the vermiculite and smectite surface area can approximate $8 \times 10^{5} \mathrm{~m}^{2} \mathrm{~kg}^{-1}$ concerning the number of structured layers in an aggregate [17]. All clay particles have a high external surface area because of their small size. The external surface area of $1 \mathrm{~g}$ of colloidal clay minerals is expected 1000 times greater than that of $1 \mathrm{~g}$ of coarse sand [9].

Surface charge: Soil colloidal particles are always in movement due to their charged particles. Colloids are reactive because of their total surface area and increased reactivity related to rough surfaces and highly energetic sites, and the effect of electrostatic charges[18,22]. Surfaces of clay colloids have positive or negative charges on their surfaces to attract charged ions, but negative charges predominate [5]. Soil colloidal particles can absorb different phases from their suspension. Humus and clay mineral cations and anions are adsorbed on their surfaces because of permanent negative charges of clays formed by isomorphous substitution [9].

The charge on the mineral surface is calculated as the difference between the moles of charge donated per unit mass of mineral by the positive and negative anions adsorbed from an electrolyte solution of known $\mathrm{pH}$. The positive and negative charge adsorbed give rise to a cation exchange capacity (CEC) and anion exchange capacity (AEC) in centi mol charge per $\mathrm{kg}$. Clay minerals such as kaolinite, and the surfaces of $\mathrm{Fe}$ and $\mathrm{Al}$ oxides have $\mathrm{pH}$-dependent charges [12]. Permanent charges of silicate layers resulted from isomorphous substitutions [19].

Plasticity: Plasticity is the capacity of clay particles to be easily molded when it moist or wet. Soils that contain greater than $15 \%$ clay show a plasticity manner [9]. This property is may be due to the plastic-like nature of the clay particles. Plasticity is exhibited when soils are wet or moist [9].

Cohesion: When the water content of too wet clay is decreased, the attraction of colloidal particles will seem to increase. This situation of the clay particles to aggregate probably is due to the attraction of the clay particles for the available water held between the clay particles. Soil colloidal particles have cohesion and adhesion properties [9].

Citation: Alemayehu B, Teshome H (2021) Soil Colloids, Types and their Properties: A review. Open J Bioinform Biostat 5(1): 008-013. 
Swelling and shrinkage: Swelling is the process of expansion of crystal layers that occurs because of water moving between crystal layers. Swelling is considered by water attracted to ions and adsorbed by clays and water entered in soil pore spaces soils [9]. Swelling occurs when the soil has small particle sizes like smectite (e.g. montmorillonite) upon which extreme expanding happens when upon wetting. However, Kaolinite, chlorite, fine mica, do not show this characteristic to any extent, and also vermiculite is in between. The swelling property of certain clays can be change volume by adsorbing water into their structure [23].

Dispersion and flocculation: The term flocculation refers to the action by which individual fine soil particles are come to sticking together to form flocculates [9]. A principal manner of a dilute colloidal suspension in water is complete dispersion means that the particles repel one with the other [9].

\section{Conclusion}

Soil colloids are the most active site of the soil which includes organic and inorganic clay. colloids are small particlesized minerals, having large external surface area, high CEC, the internal and external soil colloids surface carried negative and/or positive charges, and also the individual particle mostly spherical, non-structured, or no crystalline. Silica is the major structural element contained in many mineral soils. Soil colloids can be identified one from the other based on their composition, tetrahedral arrangement, and octahedral sheets of silica and also alumina. Soil colloids are very vital for nutrient reserving which contributes to most essential plant nutrients not be removed by the percolating water. This review paper will contribute as a baseline for soil science scholars and related fields. Further research on soil colloids and their properties is essential for more understanding in the practical management of soils.

\section{Ethical declaration}

The review paper is an original work carried out by ourselves. The matter embodied in this review work has not been submitted earlier for publication in other journals.

\section{References}

1. Lewis BG (2009) Soil chemistry. Environmental and Ecological ChemistryVolume 2: 78 .

2. Elias E (2016) Soils of the Ethiopian Highlands: Geomorphology and Properties. CASCAPE Project, ALTERA, Wageningen University and Research Centre (Wageningen UR). The Netherlands. 385. Link: https://bit.ly/3s4T3jO

3. Foth HD (1978) Fundamentals of soil science. Soil Science 125: 272. Link: https://bit.ly/3ixu0CX

4. Liu G, Wang J, Xue W, Zhao J, Wang J, et al. (2017) Effect of the size of variable charge soil particles on cadmium accumulation and adsorption. Journal of Soils and Sediments 17: 2810-2821. Link: https://bit.ly/3s6ybst
5. Brady NC, Weil RR, Weil RR (2008) The nature and properties of soils. Upper Saddle River, NJ: Prentice-Hall 13. Link: https://bit.ly/3AkZTES

6. Uddin F (2018) Montmorillonite: An Introduction to Properties and Utilization. Current Topics in the Utilization of Clay in Industrial and Medical Applications 1. Link: https://bit.ly/2VyR7Vb

7. Karathanasis AD (2006) Soil mineralogy. Land use and land cover, from Encyclopedia of Life Support Systems (EOLSS). Link: https://bit.ly/37A1oCN

8. Noack AG (2002) Mobility of colloids in soils/by Angela Gai Noack (Doctoral dissertation).

9. Brady NC, Weil RR (1984) Nature and properties of soils, Macmillan Publishers Co. INC, New York.

10. Barton CD (2002) Clay minerals. In: Rattan Lal, comp., ed. Encyclopedia of Soil Science. New York, New York: Marcel Dekker: 187-192. Link: https://bit.ly/3Cs3pz0

11. Hillel D (1998) Environmental Soil Physics: Fundamentals, Applications, and Environmental Considerations. Elsevier. Link: https://bit.ly/3xvdqld

12. White R (2006) Principles and Practice of Soil Science The Soil as a Natura Resource, Blackwell Publishing, Malden, $4^{\text {th }}$ Edn 32.

13. De Haro MJ, Pérez-Rodríguez JL, Poyato J, Pérez-Maqueda LA, Ramírez-Valle $\checkmark$, et al. (2005) Effect of ultrasound on preparation of porous materials from vermiculite. Applied Clay Science 30: 11-20. Link: https://bit.ly/2U4BBzl

14. Gupta V, Hampton MA, Stokes JR, Nguyen AV, Miller JD (2011) Particle interactions in kaolinite suspensions and corresponding aggregate structures. J Colloid Interface Sci 359: 95-103. Link: https://bit.ly/3s6xCPn

15. Al-Ani T, Sarapää O (2008) Clay and clay mineralogy. Physical-chemical Properties and Industrial Uses. Link: https://bit.ly/3fR1TNb

16. Brown G (1984) Crystal structures of clay minerals and related phyllosilicates. Philosophical Transactions of the Royal Society of London. Series A, Mathematical and Physical Sciences 311: 221-240. Link: https://bit.ly/3AuxBaZ

17. Sposito G (2008) The chemistry of soils. Oxford university press. Link: https://bit.ly/37yJTTc

18 Goldberg S, Lebron I, Seaman JC, Suarez DL (2012) Soil colloida behavior. Handbook of Soil Sciences Properties and Processes, $2^{\text {nd }}$ ed.; Huang PM, Li Y, Sumner ME, Eds. Link: https://bit.ly/3iADmOh

19. Lagaly G, Ziesmer S (2003) Colloid chemistry of clay minerals: the coagulation of montmorillonite dispersions. Advances in Colloid and Interface Science 100 105-128. Link: https://bit.ly/2U6Bzal

20. Klein C, Philpotts AR (2013) Earth materials: introduction to mineralogy and petrology. Cambridge University Press. https://bit.ly/3iwVEzQ

21. Stevenson FJ, Olsen RA (1989) A simplified representation of the chemical nature and reactions of soil humus. Journal of Agronomic Education 18: 8488. Link: https://bit.ly/3CwEeLL

22. Lebron I, Seaman JC (2011) Sabine Goldberg United States Department of Agriculture. Handbook of Soil Sciences: Properties and Processes.

23. Newman AC (1987) Chemistry of clays and clay minerals. Longman Scientific \& Technical 480. Link: https://bit.ly/3CCqzTI

Copyright: @ 2021 Alemayehu B, et al. This is an open-access article distributed under the terms of the Creative Commons Attribution License, which permits unrestricted use, distribution, and reproduction in any medium, provided the original author and source are credited.

Citation: Alemayehu B, Teshome H (2021) Soil Colloids, Types and their Properties: A review. Open J Bioinform Biostat 5(1): 008-013. 